\title{
Progressive Decline in Daily and Social Activities: A 9-year Longitudinal Study of Participation in Myotonic Dystrophy Type 1
}

\author{
Kateri Raymond, MOT, ${ }^{a, b, c, d}$ Mélanie Levasseur, PhD, ${ }^{a, c}$ Jean Mathieu, $\operatorname{FRCP}(C){ }^{a, b, d}$ \\ Cynthia Gagnon, PhD ${ }^{a, b, d}$
}

From the ${ }^{a}$ School of Rehabilitation, Faculty of Medicine and Health Sciences, Université de Sherbrooke, Sherbrooke, Québec; ${ }^{b}$ Groupe de recherche interdisciplinaire sur les maladies neuromusculaires (GRIMN), Neuromuscular Clinic, Centre intégré universitaire de santé et de services sociaux du Saguenay-Lac-St-Jean, Jonquière, Québec; ${ }^{C}$ Research Centre on Aging, Centre intégré universitaire de santé et de services sociaux de l'Estrie-Centre hospitalier universitaire de Sherbrooke, Sherbrooke, Québec; ${ }^{d}$ Centre de recherche Charles-Le Moyne - SaguenayLac-Saint-Jean sur les innovations en santé (CR-CSIS), Centre intégré universitaire de santé et de services sociaux du Saguenay-Lac-St-Jean, Chicoutimi, Québec, Canada.

\begin{abstract}
Objective: To describe and compare changes in participation over a 9-year period in women and men with myotonic dystrophy type 1 (DM1). To compare participation restrictions with available reference values from a typical aging population living in the community.

Design: Descriptive longitudinal design comparing data from baseline (2002) with data from follow-up (2011).

Setting: Neuromuscular clinic and participant's home.

Participants: Adults with DM1 participated in the follow-up study $(\mathrm{N}=115)$.

Interventions: Not applicable.

Main Outcome Measure: The Assessment of Life Habits measured participation in 10 domains of daily and social activities. The minimal clinically important difference is 0.5 on a 10-point scale for participation accomplishment level.

Results: A total of $62 \%$ of participants were women, and the mean age was $52.3 \pm 10.3$ years. A decline $(P<.01)$ was observed with increasing difficulty and assistance required in global participation (mean $\pm \mathrm{SD},-0.5 \pm 0.9$ ), social activities subscore $(-0.6 \pm 1.2)$, nutrition $(-0.7 \pm 1.4)$, fitness $(-1.0 \pm 1.6)$, personal care $(-0.7 \pm 1.2)$, mobility $(-0.5 \pm 1.9)$, community life $(-0.8 \pm 1.9)$, and recreation $(-1.5 \pm 3.0)$. More life areas are disrupted over time: 8 domains were below reference values from a population aged 55-64 years at follow-up compared with 2 domains at baseline. Satisfaction with participation remains high and stable over time.

Conclusion: As disease duration increases, global participation and more daily and social domains were restricted with increasing difficulty and assistance required. Adults with DM1 showed not only age-associated but disease-specific changes in participation. Description over time of participation could improve clinical assessment and guide interdisciplinary management of DM1, leading to higher rehabilitation success. Further investigation of the factors influencing changes in participation is required to support disease management and services planning.
\end{abstract}

Archives of Physical Medicine and Rehabilitation 2019;100:1629-39

(C) 2019 by the American Congress of Rehabilitation Medicine

\footnotetext{
Presented as a poster to the ler congrès québécois de recherche en adaptation-réadaptation, May 21-22, 2015, Boucherville, Québec, Canada, and as an oral presentation to the International Myotonic Dystrophy Consortium, June 8-12, 2015, Paris, France.

Study was performed at the Clinique des maladies neuromusculaires de Jonquière, Centre intégré universitaire de santé et de services sociaux du Saguenay-Lac-St-Jean.

Disclosures: C.G. received honorarium for conference presentation and data sharing for preparation of therapeutic trial from Biogen Idec. The other authors have nothing to disclose.

Supported by the Canadian Institutes of Health Research (CIHR) (grant no. MOP-49556, JNM-108412) and Muscular Dystrophy Canada. At the time of the study, this work was supported by the Université de Sherbrooke and the Fonds de recherche du Québec-Santé (FRQS) (grant no. 22193, 26815). At the moment, authors are supported by the FRQS (grant no. 30844,31011 ) and the CIHR (grant no. $360880)$.
} 
Myotonic dystrophy type 1 (DM1) is the most prevalent neuromuscular disorder in adults. ${ }^{1}$ DM1 is a dominant hereditary multisystemic disease with high heterogeneity in the clinical picture. $^{2}$ The large variability within and between individuals in terms of signs and symptoms has led to a classification into 4 or 5 phenotypes: congenital, childhood, juvenile (or early adult), adult, and late-onset. ${ }^{3-5}$ This disease is usually characterized by progressive muscle weakness, myotonia, fatigue, dysphagia, cognitive impairment, and a plethora of other potential signs and symptoms. $^{2}$ The pattern of involvement and progression of the disease has led several teams to compare DM1 with a premature aging population. ${ }^{6-8}$ Furthermore, quality of life ${ }^{9,10}$ and participation ${ }^{11}$ are often jeopardized for people with DM1. As a measure of rehabilitation success, ${ }^{12-14}$ participation can be defined with the Human Development Model-Disability Creation Process (HDMDCP) framework as the accomplishment of daily activities and social roles resulting from the interaction of personal and environmental factors. ${ }^{15}$ Because social roles are not defined in the typical sense (eg, role of father) but with observable activities, ${ }^{16}$ the term social activities is used in this article.

Participation restrictions in daily and social activities secondary to DM1 may have significant individual, societal, and financial consequences. For instance, quality of life has been associated with participation. ${ }^{17}$ Medical, nonmedical, and indirect costs of \$32,236 per year were estimated in the United States. ${ }^{18}$ Because no cure is available yet, long-term interdisciplinary care is required to optimize participation. ${ }^{19}$ Indeed, participation restrictions in DM1 could be prevented or diminished by health care and community services. ${ }^{20}$ Long-term management may include maintaining physical capacity with exercise programs ${ }^{21,22}$ or environmental adaptations. ${ }^{23}$

One cross-sectional study found that individuals with the adult and late-onset phenotypes experience participation restrictions mainly in employment, housing (ie, home maintenance), mobility, and recreation. ${ }^{11}$ Similar results were found for activities related to housing, community life, and recreation. ${ }^{24}$ As the disease progresses, individuals with DM1 and their close relatives modify their activities, ${ }^{25}$ usually giving up physically demanding ones ${ }^{26}$ and performing others partially. ${ }^{27}$ Additionally, longitudinal studies found a decline in the performance of activities related to personal care, housing, mobility, and recreation. ${ }^{9,28}$ Although this is important information for the long-term management of the disease, no study has considered changes in communication, responsibilities, interpersonal relationships, and community life. Considering the slow progression, ${ }^{29}$ it makes sense to examine participation over a lengthier time period. ${ }^{30}$ Moreover, although DM1 is distributed equally between women and men, ${ }^{2}$ a sex difference is shown for the presence of multiple symptoms ${ }^{31}$ and for progressive muscle weakness. ${ }^{29,32,33}$ To our knowledge, no research has studied long-term participation changes or considered sex difference over time for individuals with DM1.

\section{List of abbreviations: \\ CTG cytosine-thymine-guanine \\ DM1 myotonic dystrophy type 1 \\ HDM-DCP Human Development Model-Disability Cre- ation Process \\ ICC intraclass correlation coefficient \\ LIFE-H Assessment of Life Habits \\ MCID minimal clinically important difference \\ MIRS Muscular Impairment Rating Scale \\ RM-ANOVA repeated measures analysis of variance}

Thus, this study aimed to describe changes in participation over a 9-year period in adults with DM1 and to explore sex discrepancy. As an exploratory objective, this study also compared participation in adults with DM1 with available reference values from a typical aging population as an alternative to compare with a general population control group. Three hypotheses were formulated, namely, participation restrictions in individuals with DM1 should (1) increase over time, (2) be different according to sex, and (3) be greater than the typical aging population.

\section{Methods}

\section{Design and participants}

This descriptive longitudinal study compared baseline (2002-2004) and follow-up (2011-2013) assessments of adults with DM1 registered at a neuromuscular clinic. At baseline, 200 adults took part in the study, and recruitment has been described elsewhere. ${ }^{11,34}$ French-speaking individuals 18 years or older with the adult (including juvenile) or late-onset phenotypes confirmed by genetic analysis were included. Congenital and childhood phenotypes were excluded because they presented with earlier onset, more severe impairment, ${ }^{35}$ and different prognoses. ${ }^{36}$ Participants had late-onset if they presented with at least 2 of the following: (1) <200 cytosinethymine-guanine (CTG) repeats, 2) a Muscular Impairment Rating Scale (MIRS) score of 1 (no muscular impairment) or 2 (minimal signs), or (3) the patient's report of frequent symptoms related to DM1 (eg, muscle strength, myotonia, or cataract) occurred after age 40. Otherwise, participants were classified as having the adult form of DM1, which included the juvenile phenotype at the time of the study. Individuals with another condition influencing participation (eg, stroke) were excluded. For the follow-up, individuals were excluded if they could not give informed consent (eg, developed dementia) following a screening for potential new health problems which was carried out by their nurse case manager. The study was conducted at the neuromuscular clinic and the participant's home. Consent was obtained at both assessment times, and the Ethics Review Board approved the study (\#2010-046).

\section{Measurements}

Data collection procedures, including the questionnaire administration sequence and the time of the year (Nordic climate), were kept as similar as possible for both measurements. To limit interrater disagreement, the rater of the first measurement trained the rater of the second measurement. Also, standardized procedures and examples were used. At the neuromuscular clinic, sociodemographic and clinical characteristics of participants as well as disease duration were collected by a research assistant. The number of CTG repeats was assessed using a standard procedure. ${ }^{34}$ Overall progression of muscular impairment was measured using the DM1-specific MIRS based on manual muscle testing and the presence of myotonia. ${ }^{37}$ Stages $1-5$ indicated no muscular impairment to severe proximal weakness. ${ }^{37}$

A number of participation definitions exist, and the tool used to assess participation must be consistent with them. ${ }^{38}$ No specific DM1 participation assessment tools existed at the beginning of the study. ${ }^{39}$ Among existing definitions, the HDM-DCP framework provided a concrete and mutually exclusive definition of the components related to participation, activities, and capacities 


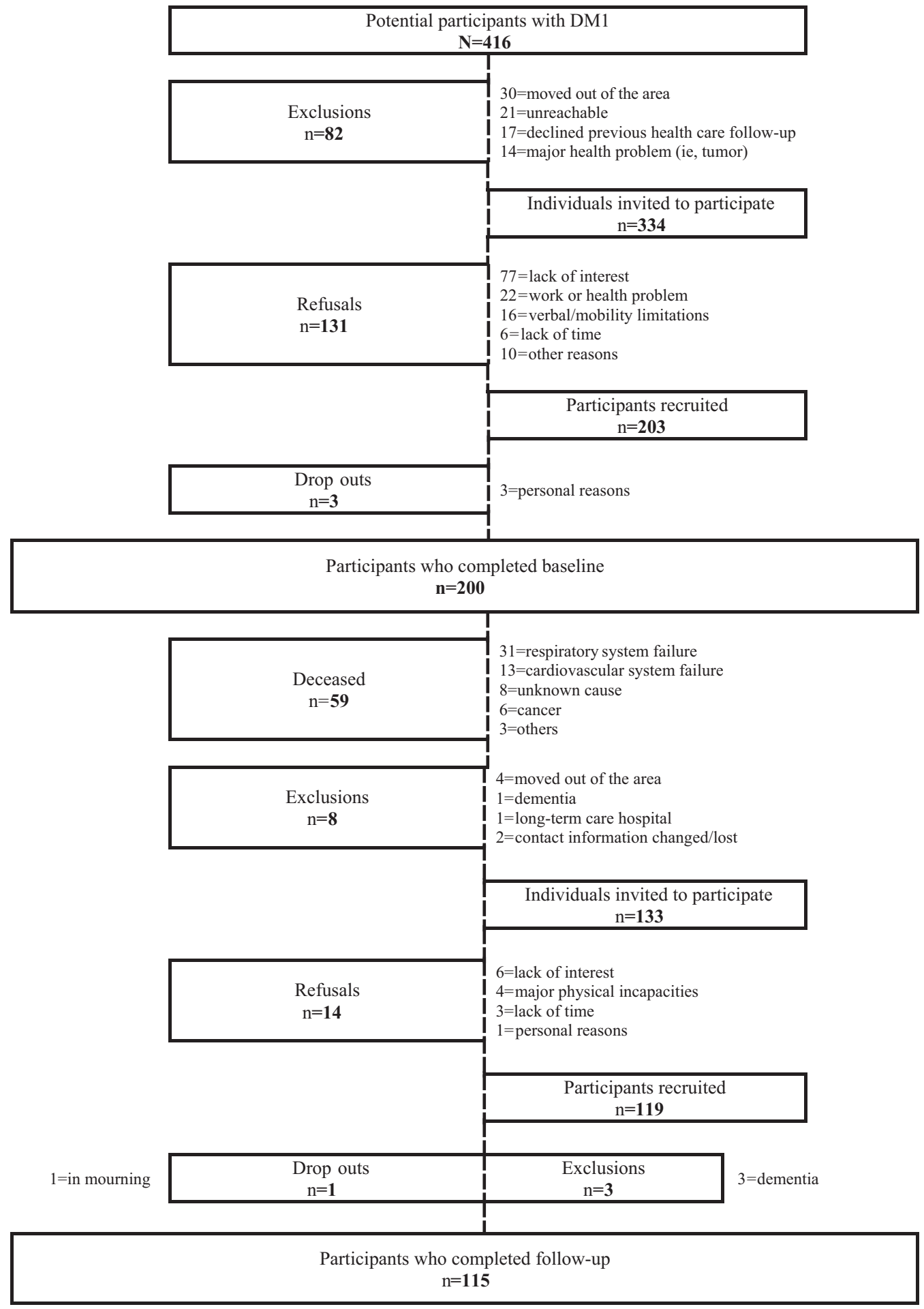

Fig 1 Participants' flow chart.

compared with other models, such as the International Classification of Functioning, Disability and Health. ${ }^{40}$ Based on the HDM-DCP framework, the short 3.1 version of the Assessment of Life Habits questionnaire (LIFE-H) was used to assess participation. ${ }^{41}$ Psychometric properties of the LIFE-H 3.1 have been documented in the DM1 population. It was completed at the participant's home and administered by one trained occupational therapist at baseline and another at follow-up. This questionnaire includes 77 items (ie, activities) covering the 12 domains of participation (number of activities): nutrition (4), fitness (4), personal care (8), communication (8), housing (8), mobility (5), responsibilities (8), interpersonal relationships (7), community life (8), education (2), employment (8), and recreation (7). The first 6 domains refer to participation in daily activities and the last 6 to 
participation in social activities. Scores are provided for each domain, 2 subscores (daily and social activities), and the total score (global participation). Because no participant was at school and only 20 of them were employed, the education and employment domains were not analyzed, and results are not shown. The questionnaire considers accomplishment level and satisfaction level in participation. Accomplishment level is assessed with a 10point scale from 9-0, using level of difficulty and assistance required as participation's indicators (supplemental table S1, available online only at http://www.archives-pmr.org/). A change of $0.5(/ 9)$ is considered a minimal clinically important difference (MCID). ${ }^{42}$ Also, a score of $\leq 7$ indicates a disruption (ie, accomplished with difficulty), while a score of $\leq 5$ indicates a severe disruption (ie, accomplished with human assistance). ${ }^{41}$ These cutoffs give a clinical comprehension of accomplishment level in participation. Satisfaction level is assessed with a 5-point scale from 1-5, with a higher mean score indicating greater satisfaction (see supplemental table S1). There is no known MCID for satisfaction change. For DM1, the LIFE-H shows excellent reliability for domains, subscores, and total score, with intraclass correlation coefficients (ICCs) ranging from 0.80-0.91 for intrarater reliability and $0.86-0.92$ for interrater reliability. ${ }^{43}$ Poor intrarater and interrater reliability were found for 2 domains: fitness (ICC, 0.20 and 0.21 , respectively) and communication (ICC, 0.12 and 0.47 , respectively). However, these domains showed excellent agreement according to Bland and Altman graphs, indicating that this may be because of the homogeneity of the sample. The LIFE-H showed validity with various populations. ${ }^{44-46}$

\section{Data analysis}

Descriptive statistics were used to define the participants. To document selection bias, baseline characteristics of the individuals who participated at baseline but did not attend follow-up, hereinafter named lost to follow-up, were compared with the baseline characteristics of participants using the Mann-Whitney test (continuous variables) or chi-square test (nominal variables). There were no missing data for participation except for nutrition and recreation $(<5 \%)$. With respect to the assumption of sphericity, repeated measures analysis of variance (RM-ANOVA) was used to compare follow-up (T2) with baseline (T1) for accomplishment and satisfaction. Within-participant effects, a subtest of RM-ANOVA, allowed exploratory comparison of changes in accomplishment for sex subgroup. To detect clinical changes, a mean difference in accomplishment $(\Delta=\mathrm{T} 2-\mathrm{T} 1)$ was calculated and compared with the MCID. Also, descriptive analyses were used to estimate the proportion and percentage of participants with decreased $(\leq \mathrm{MCID})$ or improved ( $\geq$ MCID) participation over the 9-year interval. A comparison with typical aging reference values ${ }^{47}$ was performed using Wilcoxon rank-sum test. Reference values were chosen because they were collected with the same assessment procedure in the Quebec population, the most similar population to ours. However, values were only available for adults 55 years or older within a cross-sectional design. Reference values of the group aged 55-64 years (the closest to the participants' age) were chosen for comparison. The latter was performed with the whole DM1 sample as an exploratory objective, no matter how old participants were, to better inform on the participants' level of participation. It is worth noting that education and employment domains are also excluded from these reference values because they are often not applicable for older adults. Cutoffs were used to determine the proportion of participants with disrupted and severely disrupted participation over time, while McNemar chi-square test was used to compare changes over time. As a supplemental descriptive and exploratory analysis, changes in the activities in each domain were explored with RMANOVA and compared with the MCID. The statistical analyses were performed using SPSS $^{\mathrm{a}}$ software (version 21.0 for Windows), and $\alpha=0.05$ was used.

\section{Results}

Of the 200 participants at baseline, 115 completed the study 9 years later (fig 1). The participants who completed follow-up did not differ at baseline from the 85 lost to follow-up in terms of sex, CTG, and phenotypic distribution. However, compared with participants, lost to follow-up were older at baseline $(51.6 \pm 12.1$ vs $43.6 \pm 10.3$ years old; $P<.01)$, had greater disease severity according to the MIRS $(P<.001)$, and were more restricted in their participation at baseline for each domain, subscores, and the total score $(P<.01)$. The 59 participants who died before the follow-up did not differ from the 26 who were excluded or refused to participate in term of $\operatorname{sex}(P=.638)$ but were older $(P=.002)$ and presented greater disease severity $(P<.001)$. The 26 participants excluded or who refused to participate were not different from the 115 participants in terms of sex, age, and disease severity $(P>.05)$. A total of $62 \%$ of participants were women (table 1) aged 29-85 years with a disease duration ranging from 12-47 years. Most participants were living at home with a spouse or other relatives, had a family income of less than $\mathrm{C} \$ 19,999$, and were receiving community services (eg, household assistance, meal delivery). The housing situation of half of the participants changed during the study. One person was living in a long-term care facility at baseline and an additional 3 were at follow-up.

Participation decreased over 9 years for the total score, social activities subscore, and 6 domains: nutrition, fitness, personal care, mobility, community life, and recreation (table 2). Recreation showed the greatest decline (ie, triple the MCID). Based on standard deviation of delta, individual trajectories of participation differ. At follow-up, no participants showed a complete disruption of participation (0/9) except for recreation $(6.3 \%)$.

Participants reported to be "satisfied" and "very satisfied" at both measurements for global participation, daily and social activities subscores, and all domains (see table 2). Satisfaction was stable over time for all domains.

Women and men were similar with respect to age and disease duration (supplemental table S2, available online only at http://www. archives-pmr.org/). Participation change over 9 years was mostly similar for both sexes on a statistical point of view. A trend worth noting was men's changes in each domain were consistently greater than women's. The latter almost improved over time for housing while men declined. However, men showed a greater clinical decline (above MCID) than women only for fitness (table 3).

When compared with typical aging adults aged 55-64 years, ${ }^{47}$ participation as well as daily and social activities were similar to reference values at baseline but lower at follow-up even though participants were younger at follow-up $(52.3 \pm 10.3 \mathrm{y}$ vs $60.4 \pm 3.1 y$; see table 2). More specifically, fitness, mobility, and community life were already below reference values at baseline. In addition to these 3 domains, personal care and recreation were also below reference values at follow-up.

More than one-third of participants showed a decrease in participation, daily and social activities, and all domains except 
for communication, responsibilities, and interpersonal relationships (see table 2). For housing, a decrease was observed in about one-third of participants over the 9-year period, while an increase was observed in approximately another third. For mobility, a similar pattern to housing was observed.

Compared with baseline, a greater disruption in participation was found at follow-up, with more than 1 participant of 10 showing a disruption in almost all participation scores (table 4). A more severe disruption (ie, requiring human assistance) was found specifically in nutrition, fitness, mobility, community life, and recreation at follow-up.

Among daily activities, activities with the largest clinical change in each domain were preparing meals, participating in physical activities to maintain fitness, putting on an assistive device and attending to personal hygiene, maintaining the home and grounds, and riding a bicycle (supplemental table S3, available online only at http://www.archives-pmr.org/). Among social activities, those with the largest clinical change were making purchases, having a sexual relationship, using public services and neighborhood businesses, taking part in outdoor activities, and participating in sporting or recreational activities.

\section{Discussion}

This study is the first to assess participation changes over a 9-year period in adults with DM1, explore sex discrepancy, and make comparisons with reference values from a typical aging population. Partially confirming the first hypothesis, individuals with DM1 experienced more restrictions in participation over time but not all participants nor in all domains. Similar for both sexes, 6 domains of participation (4 daily activities [nutrition, fitness, personal care, mobility] and 2 social activities [community life and recreation]) decreased. Clinical improvement and decline were found almost equally for housing and mobility. Although a trend for men having higher decline than women was identified, the second hypothesis was infirmed because almost no clinical difference for decline was found between women and men. At follow-up, most scores were below reference values from a typical aging population aged 55-64 years, partially confirming the third hypothesis. These results are of importance because they have the potential to guide long-term intervention targeting participation and to better inform health care professionals and families about the disease prognosis.

\section{Participation accomplishment level}

A decrease in global participation as well as in social activities for adults with DM1 was expected. Of the 6 domains that decreased over 9 years, only 3 were highlighted in previous studies. ${ }^{9,28}$ This study was the first to document a decline in nutrition, fitness, and community life, whereas housing, communication, responsibilities, and interpersonal relationships were stable. Contrary to the current findings, Bostrom et $\mathrm{al}^{28}$ reported no change over a 10 -year period in eating (included in nutrition), sleep, and rest (included in fitness) and a decrease in home maintenance (included in housing) for 25 participants with DM1. However, they ${ }^{28}$ measured activity limitations (Sickness Impact Profile ${ }^{48}$ ), which covers only some items from the LIFE-H.

Surprisingly, in the current study, a significant proportion of people showed an improvement for housing and mobility. Because participation results from the interaction of personal and environmental
Table 1 Participants' characteristics $(\mathrm{N}=115)$

\begin{tabular}{|c|c|c|}
\hline Characteristics & Baseline (T1) & Follow-up (T2) \\
\hline Age $(y)$ & $43.6 \pm 10.3$ & $52.3 \pm 10.3$ \\
\hline Sex (women) & $72(62.6)$ & \\
\hline \multicolumn{3}{|l|}{ Phenotype } \\
\hline Adult & $90(78.3)$ & \\
\hline Late-onset & $25(21.7)$ & \\
\hline CTG & $771 \pm 518$ & $916 \pm 508$ \\
\hline [Range] & {$[55-2000]$} & [116-1897] \\
\hline $50-200$ & $23(20.0)$ & $13(11.3)$ \\
\hline $201-1000$ & $55(47.8)$ & $36(31.3)$ \\
\hline$>1000$ & $37(32.2)$ & $64(55.7)$ \\
\hline Missing & & $2(1.7)$ \\
\hline $\begin{array}{l}\text { Disease duration }(y) \\
\quad \text { Missing }(n=34,29.6 \%)\end{array}$ & $19.9(8.1)$ & $28.8(8.1)$ \\
\hline \multicolumn{3}{|l|}{ MIRS } \\
\hline Grade 1 & $6(5.2)$ & $1(0.9)$ \\
\hline Grade 2 & $14(12.2)$ & $5(4.3)$ \\
\hline Grade 3 & $27(23.5)$ & $23(20.0)$ \\
\hline Grade 4 & $62(53.9)$ & $66(57.4)$ \\
\hline Grade 5 & $5(4.3)$ & $13(11.3)$ \\
\hline Missing & $1(0.9)$ & $7(6.1)$ \\
\hline \multicolumn{3}{|l|}{ Family income (Canadian \$) } \\
\hline$<10,000$ & $20(17.4)$ & $11(9.6)$ \\
\hline $10,000-19,999$ & $38(33.0)$ & $51(44.3)$ \\
\hline $20,000-39,999$ & $20(17.4)$ & $24(20.9)$ \\
\hline $40,000-59,999$ & $10(8.7)$ & $16(13.9)$ \\
\hline$>60,000$ & $18(15.6)$ & $12(10.4)$ \\
\hline Unknown/refused & $9(7.8)$ & $1(0.9)$ \\
\hline \multicolumn{3}{|l|}{ Education level $(y)$} \\
\hline$\leq 11$ & $50(43.5)$ & $50(43.5)$ \\
\hline $12-13$ & $49(42.6)$ & $49(42.6)$ \\
\hline $14-16$ & $14(12.1)$ & $12(10.4)$ \\
\hline$\geq 17$ & $2(1.7)$ & $4(3.5)$ \\
\hline \multicolumn{3}{|l|}{ Living arrangement } \\
\hline Home alone & $19(16.5)$ & $32(27.8)$ \\
\hline Home with spouse or other(s) & $95(82.6)$ & $79(68.7)$ \\
\hline Long-term care facility & $1(0.9)$ & $4(3.5)$ \\
\hline \multicolumn{3}{|l|}{ Residence characteristics } \\
\hline Ground floor & $37(32.2)$ & $72(62.6)$ \\
\hline Basement or upper floors & $78(67.8)$ & $43(37.4)$ \\
\hline Relocation during study & $57(49.6)$ & \\
\hline \multicolumn{3}{|l|}{ Receiving community services } \\
\hline Household assistance & $50(43.5)$ & $56(48.7)$ \\
\hline Adapted transportation & $21(18.3)$ & $26(22.6)$ \\
\hline Meals delivery service & $15(13.0)$ & $8(7.0)$ \\
\hline Home adaptation & $16(13.9)$ & $17(14.8)$ \\
\hline
\end{tabular}

NOTE. Values expressed as mean \pm SD for continuous variables and frequency (\%) for categorical variables.

factors, ${ }^{15}$ better participation over time could be explained by several factors. For example, adaptation to impairment (eg, a response-shift implying shifting internal reference system, such as values and coping with a disease, which has been documented in other progressive disease and during the aging process ${ }^{49,50}$ ), care improvement (eg, over the 9-year period, a home health service was implemented at the neuromuscular clinic where the study took place), or a change in physical environment (eg, half of the cohort moved within the 9-year period, and, of them, $61 \%$ moved from basement or upper floor to a 
Table 2 Comparison of participation and satisfaction scores at baseline and follow-up $(\mathrm{N}=115)$

\begin{tabular}{|c|c|c|c|c|c|c|c|c|c|c|}
\hline \multirow[b]{2}{*}{ Participation Score (/9) } & \multirow[b]{2}{*}{ Reference Values* } & \multirow[b]{2}{*}{$\mathrm{T} 1$} & \multirow[b]{2}{*}{ T2 } & \multirow[b]{2}{*}{$\Delta^{\dagger}$} & \multirow[b]{2}{*}{$P$} & \multirow[b]{2}{*}{ Decrease $^{\S}$} & \multirow[b]{2}{*}{ Improvement $\|$} & \multicolumn{3}{|c|}{ Satisfaction Score $(/ 5)$} \\
\hline & & & & & & & & $\mathrm{T} 1$ & T2 & $P$ \\
\hline Participation (total score) & $8.4 \pm 0.3$ & $8.3 \pm 0.8$ & $7.8 \pm 1.2^{\#}$ & $-0.51 \pm 0.9^{* *}$ & $<.001$ & $39(33.9)$ & $7(6.1)$ & $4.5 \pm 0.5$ & $4.5 \pm 0.4$ & .06 \\
\hline Daily activities & $8.3 \pm 0.3$ & $8.2 \pm 0.8^{\pi}$ & $7.8 \pm 1.2^{\#}$ & $-0.43 \pm 0.9$ & $<.001$ & $40(34.8)$ & $8(7.0)$ & $4.5 \pm 0.5$ & $4.5 \pm 0.4$ & .14 \\
\hline Nutrition $(n=113)$ & $8.1 \pm 1.3$ & $8.5 \pm 0.8^{\dagger \dagger}$ & $7.8 \pm 1.8^{\pi}$ & $-0.72 \pm 1.4^{* *}$ & $<.001$ & $38(33.6)$ & $5(4.4)$ & $4.6 \pm 0.5$ & $4.7 \pm 0.4$ & $<.01$ \\
\hline Fitness & $8.7 \pm 0.5$ & $8.1 \pm 1.2^{\#}$ & $7.1 \pm 1.7^{\#}$ & $-1.00 \pm 1.6^{* *}$ & $<.001$ & $63(54.8)$ & $14(12.2)$ & $4.2 \pm 0.7$ & $4.1 \pm 0.8$ & .23 \\
\hline Personal care & $8.9 \pm 0.1$ & $8.7 \pm 0.6^{\pi}$ & $8.0 \pm 1.4^{\#}$ & $-0.68 \pm 1.2^{* *}$ & $<.001$ & $43(37.4)$ & $5(4.3)$ & $4.6 \pm 0.5$ & $4.7 \pm 0.5$ & .20 \\
\hline Communication & $8.4 \pm 0.5$ & $8.7 \pm 0.5^{\dagger \dagger}$ & $8.6 \pm 1.0^{\dagger \dagger}$ & $-0.10 \pm 1.0$ & .26 & $19(16.5)$ & $12(10.4)$ & $4.6 \pm 0.5$ & $4.6 \pm 0.4$ & .23 \\
\hline Housing & $7.5 \pm 0.9$ & $7.5 \pm 1.5^{\llbracket}$ & $7.4 \pm 1.5^{\mathbb{q}}$ & $-0.09 \pm 1.4$ & .50 & $36(31.3)$ & $33(28.7)$ & $4.4 \pm 0.6$ & $4.5 \pm 0.5$ & .09 \\
\hline Mobility & $8.3 \pm 0.7$ & $7.5 \pm 1.7^{\#}$ & $7.0 \pm 2.1^{\#}$ & $-0.54 \pm 1.9^{* *}$ & $<.01$ & $50(43.5)$ & $26(22.6)$ & $4.3 \pm 0.7$ & $4.3 \pm 0.8$ & .96 \\
\hline Social activities & $8.5 \pm 0.4$ & $8.3 \pm 0.9^{\pi}$ & $7.7 \pm 1.4^{\#}$ & $-0.61 \pm 1.2^{* *}$ & $<.001$ & $44(38.3)$ & $8(7.0)$ & $4.4 \pm 0.5$ & $4.6 \pm 0.5$ & .03 \\
\hline Responsibilities & $8.4 \pm 0.8$ & $8.7 \pm 0.7^{\dagger \dagger}$ & $8.6 \pm 1.0^{\dagger \dagger}$ & $-0.16 \pm 0.8$ & .04 & $21(18.3)$ & $10(8.7)$ & $4.7 \pm 0.4$ & $4.8 \pm 0.4$ & .07 \\
\hline Interpersonal relationships & $8.4 \pm 0.8$ & $8.6 \pm 0.7^{\dagger \dagger}$ & $8.4 \pm 1.0^{\pi}$ & $-0.23 \pm 1.1$ & .02 & $25(21.7)$ & $12(10.4)$ & $4.5 \pm 0.5$ & $4.6 \pm 0.5$ & .04 \\
\hline Community life & $8.9 \pm 0.3$ & $8.5 \pm 1.1^{\#}$ & $7.7 \pm 2.0^{\#}$ & $-0.77 \pm 1.9^{* *}$ & $<.001$ & $41(35.7)$ & $12(10.4)$ & $4.5 \pm 0.5$ & $4.6 \pm 0.6$ & .08 \\
\hline Recreation $(n=111)$ & $8.3 \pm 1.2$ & $7.3 \pm 2.4^{\text {ब }}$ & $5.8 \pm 3.0^{\#}$ & $-1.53 \pm 3.0^{* *}$ & $<.001$ & $57(51.4)$ & $15(13.5)$ & $4.2 \pm 0.9$ & $4.1 \pm 1.0$ & .43 \\
\hline
\end{tabular}

NOTE. Values expressed as mean \pm SD for continuous variables and frequency (\%) for categorical variables.

* Reference values available for typical people aged 55-64 years.

Negative value indicated decrease participation score.

Repeated-measures analysis of variance.

\& Proportion of participants $(\mathrm{n}[\%])$ whose participation scores have decreased $(\leq-0.50)$ over time.

II Proportion of participants ( $\mathrm{n}[\%]$ ) whose participation scores have improved $(\geq 0.50)$ over time.

- Similar to reference values with Wilcoxon rank-sum test (not significant).

\# Below reference values with Wilcoxon rank-sum test $(P<.001)$.

** Clinical change (minimally clinically important difference $[$ MCID] $\leq-0.50$ ).

Above reference values with Wilcoxon rank-sum test $(P<.001)$. 
Table 3 Comparison participation scores changes from baseline to follow-up in women $(n=72)$ and men $(n=43)$

\begin{tabular}{|c|c|c|c|c|c|c|c|c|c|c|c|}
\hline \multirow[b]{2}{*}{ Participation Score (/9) } & \multicolumn{3}{|c|}{ Women, Mean \pm SD } & \multicolumn{3}{|c|}{ Men, Mean \pm SD } & \multirow[b]{2}{*}{$P^{\dagger}$} & \multicolumn{2}{|c|}{ Women, n (\%) } & \multicolumn{2}{|c|}{ Men, n (\%) } \\
\hline & $\mathrm{T} 1$ & T2 & $\Delta^{*}$ & T1 & T2 & $\Delta^{*}$ & & Decrease & Improvement $^{\S}$ & Decrease $^{\ddagger}$ & Improvement $^{\S}$ \\
\hline Participation (total score) & $8.2 \pm 0.8$ & $7.9 \pm 1.0$ & $-0.37 \pm 0.7$ & $8.3 \pm 0.8$ & $7.5 \pm 1.4$ & $-0.75 \pm 1.2^{\|}$ & .04 & $21(29.2)$ & $7(9.7)$ & $17(39.5)$ & $1(2.3)$ \\
\hline Daily activities & $8.2 \pm 0.8$ & $7.9 \pm 1.0$ & $-0.27 \pm 0.7$ & $8.3 \pm 0.8$ & $7.6 \pm 1.4$ & $-0.70 \pm 1.1^{\|}$ & .013 & $21(29.2)$ & $7(9.7)$ & $22(51.2)$ & $1(2.3)$ \\
\hline Nutrition ( $w: n=70$ ) & $8.5 \pm 0.9$ & $7.9 \pm 1.6$ & $-0.60 \pm 1.1^{\|}$ & $8.6 \pm 0.8$ & $7.6 \pm 2.1$ & $-0.93 \pm 1.7^{\|}$ & .21 & $23(32.9)$ & $3(4.3)$ & $15(34.9)$ & $2(4.7)$ \\
\hline Fitness & $8.0 \pm 1.3$ & $7.3 \pm 1.6$ & $-0.68 \pm 1.6^{\|}$ & $8.2 \pm 1.1$ & $6.6 \pm 1.8$ & $-1.55 \pm 1.5^{\|}$ & .013 & $35(48.6)$ & $13(18.1)$ & $28(65.1)$ & $1(2.3)$ \\
\hline Personal care & $8.7 \pm 0.5$ & $8.2 \pm 1.2$ & $-0.55 \pm 0.9^{\|}$ & $8.6 \pm 0.7$ & $7.7 \pm 1.7$ & $-0.90 \pm 1.6^{\|}$ & .12 & $26(36.1)$ & $3(4.2)$ & $17(39.5)$ & $2(4.7)$ \\
\hline Communication & $8.8 \pm 0.3$ & $8.8 \pm 0.6$ & $-0.01 \pm 0.5$ & $8.5 \pm 0.6$ & $8.3 \pm 1.5$ & $-0.25 \pm 1.4$ & .21 & $9(12.5)$ & $5(6.9)$ & $10(23.3)$ & $7(16.3)$ \\
\hline Housing & $7.4 \pm 1.5$ & $7.5 \pm 1.5$ & $0.11 \pm 1.5$ & $7.8 \pm 1.4$ & $7.3 \pm 1.5$ & $-0.42 \pm 1.1$ & .042 & $19(26.4)$ & $25(34.7)$ & $17(39.5)$ & $8(18.6)$ \\
\hline Mobility & $7.4 \pm 1.8$ & $7.0 \pm 2.1$ & $-0.41 \pm 2.0$ & $7.7 \pm 1.6$ & $7.0 \pm 2.0$ & $-0.75 \pm 1.7^{\|}$ & .44 & $27(37.5)$ & $19(26.4)$ & $23(53.5)$ & $7(16.3)$ \\
\hline Social activities & $8.3 \pm 0.9$ & $7.8 \pm 1.2$ & $-0.50 \pm 1.0^{\|}$ & $8.3 \pm 0.9$ & $7.5 \pm 1.5$ & $-0.81 \pm 1.5^{\|}$ & .19 & $28(38.9)$ & $7(9.7)$ & $18(41.9)$ & $6(14.0)$ \\
\hline Responsibilities & $8.7 \pm 0.6$ & $8.7 \pm 0.9$ & $-0.06 \pm 0.6$ & $8.7 \pm 0.8$ & $8.4 \pm 1.3$ & $-0.33 \pm 1.1$ & .08 & $10(13.9)$ & $6(8.3)$ & $11(25.6)$ & $4(9.3)$ \\
\hline Interpersonal relationships & $8.6 \pm 0.7$ & $8.5 \pm 0.8$ & $-0.07 \pm 0.9$ & $8.7 \pm 0.8$ & $8.2 \pm 1.2$ & $-0.50 \pm 1.2^{\|}$ & .036 & $12(16.7)$ & $10(13.9)$ & $13(30.2)$ & $2(4.7)$ \\
\hline Community life & $8.4 \pm 1.2$ & $7.8 \pm 2.0$ & $-0.62 \pm 1.9^{\|}$ & $8.6 \pm 0.9$ & $7.6 \pm 2.2$ & $-1.02 \pm 2.0^{\|}$ & .28 & $24(33.3)$ & $11(15.3)$ & $17(39.5)$ & $1(2.3)$ \\
\hline Recreation (w: $n=70, m: n=41$ ) & $7.4 \pm 2.5$ & $6.0 \pm 3.0$ & $-1.34 \pm 2.8^{\|}$ & $7.2 \pm 2.6$ & $5.5 \pm 3.0$ & $-1.87 \pm 3.2^{\|}$ & .36 & $34(48.6)$ & $11(15.7)$ & $24(58.5)$ & $5(12.2)$ \\
\hline
\end{tabular}

Abbreviations: $m$, men; $w$, women.

* Negative value indicated decrease participation score.

Repeated-measures analysis of variance, test of within-participant effects for sex.

₹ Proportion of participants whose participation scores have decreased $(\leq-0.50)$ over time.

$\S$ Proportion of participants whose participation scores have improved $(\geq 0.50)$ over time.

" Clinical change (MCID $\leq-0.50)$. 
Table 4 Comparison of participants experiencing disruption at baseline and follow-up $(\mathrm{N}=115)$

\begin{tabular}{|c|c|c|c|c|}
\hline & \multicolumn{2}{|c|}{ Disruption, n (\%) (Cutoff: $\leq 7$ ) } & \multicolumn{2}{|c|}{ Severe Disruption, n (\%) (Cutoff: $\leq 5)$} \\
\hline & T1 & T2 & $\mathrm{T} 1$ & T2 \\
\hline Participation (total score) & $11(9.6)$ & $23(20.0)^{*}$ & $0(0.0)$ & $5(4.3)$ \\
\hline Daily activities & $12(10.4)$ & $23(20.0)^{*}$ & $0(0.0)$ & $3(2.6)^{*}$ \\
\hline Nutrition $(n=113)$ & $10(8.8)$ & $30(26.5)^{*}$ & $1(0.9)$ & $17(15.0)^{*}$ \\
\hline Fitness & $21(18.3)$ & $53(46.1)^{*}$ & $6(5.2)$ & $19(16.5)^{*}$ \\
\hline Personal care & $1(0.9)$ & $17(14.8)^{*}$ & $0(0.0)$ & $8(7.0)^{*}$ \\
\hline Communication & $3(2.6)$ & $6(5.2)$ & $0(0.0)$ & $3(2.6)$ \\
\hline Housing & $46(40.0)$ & $44(38.3)$ & $5(4.3)$ & $8(7.0)$ \\
\hline Mobility & $37(32.2)$ & $51(44.3)^{*}$ & $14(12.2)$ & $19(16.5)$ \\
\hline Social activities & $13(11.3)$ & $31(27.0)^{*}$ & $1(0.9)$ & $7(6.1)$ \\
\hline Responsibilities & $5(4.3)$ & $10(8.7)$ & $0(0.0)$ & $2(1.7)$ \\
\hline Interpersonal relationships & $5(4.3)$ & $10(8.7)$ & $0(0.0)$ & $1(0.9)$ \\
\hline Community life & $10(8.7)$ & $24(20.9)^{*}$ & $3(2.6)$ & $15(13.0)^{*}$ \\
\hline Recreation $(n=111)$ & $39(35.1)$ & $64(57.7)^{*}$ & $18(16.2)$ & $41(36.9)^{*}$ \\
\hline
\end{tabular}

ground floor residence) may have contributed to participation improvement. Nevertheless, as the disease progressed, disruption in participation increased and new activities were disrupted over time, highlighting several considerations for medical, rehabilitation, and community services.

\section{Comparison with a typical aging population}

People of various ages with DM1 showed a lower accomplishment level on the majority of participation domains compared with a cohort of typical aging adults aged 55-64 years, ${ }^{47}$ even though they were younger at follow-up. This suggests that adults with DM1 showed not only age-related changes in participation but faced disease-specific restrictions.

Otherwise, in the current study, men showed a clinically higher decrease than women only in fitness, but this trend can be found for almost all domains. In a typical aging population, a sex difference in participation accomplishment level was identified in only 4 domains, in other words, women showed higher participation in nutrition and interpersonal relationships and lower participation in housing and mobility than men. ${ }^{47}$ No sex difference was found for the other domains, subscores, and global participation in the typical aging population.

\section{Participation satisfaction level}

Although several domains were disrupted and decreased over 9 years, satisfaction with participation was high and stable. Because greater quality of life over time had been already reported in the DM1 population, ${ }^{51,52}$ it is not completely surprising to observe stability in satisfaction level. In fact, quality of life has been more associated with satisfaction than with accomplishment for the aging population. ${ }^{49}$ Several factors could explain high and stable satisfaction, such as adaptation to the disease ${ }^{9-11,28}$ with coping strategies $^{53}$ and response shift. ${ }^{54}$

Furthermore, emotional functioning has been reported as a predictor of satisfaction with participation. ${ }^{24}$ Apathy ${ }^{55}$ and lack of disease awareness ${ }^{56}$ could also interfere with self-assessment of satisfaction. More studies should explore these hypotheses. Nevertheless, even if high satisfaction is reported by individuals with DM1, disrupted participation continues to be an important outcome of rehabilitation success because it places a heavy burden on individuals, their social network, and society.

\section{Clinical implications}

A decrease in participation domains that were usually not reported to be disrupted or at risk of a decrease over time could lead to unmet needs in interventions and services related to longterm maintenance of participation. Based on a previous study, ${ }^{11}$ a disruption in at least $10 \%$ of the sample is considered of importance for clinical care. Indeed, identification of specific disrupted activities over time might guide rehabilitation professionals' interventions. For example, as cognitive behavioral therapy with graded exercises suggested improvement in participation for the DM1 population, ${ }^{57}$ targeting specific activities could provide more concrete anchorage in a person's life to guide therapy. In fact, cognitive orientation to daily occupational performance targeting specific activities showed participation improvement in various populations ${ }^{58,59}$ and could be a promising avenue in the DM1 population. Because more people with DM1 had more difficulty or required human assistance over time, there is a need for health care or community services to be provided at the right time. Because interventions targeting participation must be personalized to implement evidence-based practice, ${ }^{60}$ health professionals might monitor specific activities with a greater decrease over time for each domain of participation.

\section{Study limitations}

To our knowledge, this is the first study using a descriptive longitudinal design with a large cohort to assess participation in DM1. However, with respect to limitations, because the majority of nonparticipants died over the 9 -year period, ${ }^{61}$ were older, and had greater disease severity, the study's first limitation was a survival bias. Although this phenomenon was similar in a previous DM1 study, ${ }^{28}$ results presented here might give a better portrait of participation in DM1. Second, generalization to younger people with DM1 may be jeopardized. Participants' disease duration was 
around 30 years, and their adaptation to the disease as well as their accomplishment level may be different from that of people with shorter disease duration. In addition, because disease duration was different for each participant, with no basal common time, the decline trajectory could not be interpreted as linear. Third, people with DM1 are known for their diminished disease awareness, ${ }^{56}$ which might influence their capacity to self-evaluate their participation with a questionnaire such as the LIFE-H, especially for less concrete domains (eg, interpersonal relationships). Fourth, given its scoring system (eg, with difficulty or no difficulty), the LIFE-H 3.1 might not detect subtle changes in difficulty level for accomplishment compared with the LIFE-H 4.0, which shaded the level of difficulty. The 2 last limits might lead to potential undetected changes over time. Also, because education and employment domains were not shown, the participation portrait remains incomplete. Fifth, the comparison with typical aging is exploratory and should be carefully interpreted considering that reference values were extracted from a cross-sectional study, for a specific age subgroup, and not from a control group. Considering the sample size, comparison was made with the whole sample and not with the subsample of the same specific age subgroup leading to potential bias. Sixth, societal changes affecting participation (eg, development of technology, changes in government policies) may have occurred since the end of the data collection. Despite the time passed since the end of data collection, we think results provide crucial information to guide interdisciplinary management of DM1 and may still improve prognosis given to family. Finally, this study only involved 2 measurements that do not inform about changes that could happen between measurement times and did not provide information about participation of people lost to follow-up. Although sex discrepancy was explored, gender (ie, a person's self-identity) was not recorded, leading to an unknown potential discrepancy for participation change according to gender.

\section{Conclusion}

New disrupted participation domains were found over the 9-year interval for adults with DM1. Housing, mobility, employment, and recreation were already known to be disrupted, ${ }^{11}$ but a decrease over time was found in global participation, social activities, and more specifically in nutrition, fitness, personal care, mobility, community life, and recreation. Because housing and mobility might be more influenced by environmental factors, both improvement and decline were found. Further investigations are needed to determine the personal and environmental factors influencing changes in participation to identify potential interventions or services that could maintain or improve it. Future studies should include $>2$ measurement times, make comparisons according to phenotype, and consider changes in education and employment domains given their importance for adulthood life. Also, longitudinal studies conducted on participation restrictions in the DM1 population using complementary disease-specific evaluation methods (ie, DM1-Activ or Individualized Neuromuscular Quality of Life Questionnaire) should be undertaken as well as comparison with general population controls. A description of participation changes may allow health care professionals to improve health services planning and the everyday life activities of individuals living with DM1.

\section{Supplier}

a. SPSS version 21.0; IBM.

\section{Keywords}

Activities of daily living; Longitudinal studies; Myotonic dystrophy; Rehabilitation; Social participation

\section{Corresponding author}

Kateri Raymond, MOT, Groupe de recherche interdisciplinaire sur les maladies neuromusculaires, Centre intégré universitaire de santé et de services sociaux du Saguenay-Lac-St-Jean, 2230, rue de l'Hôpital, C.P. 1200, Jonquière (Québec) G7X 7X2, Canada. E-mail address: Kateri.Raymond@USherbrooke.ca.

\section{Acknowledgments}

We thank Éric Gagnon, O.T. M.Sc., who contributed to data collection, as well as Johanne Desrosiers, O.T. Ph.D. and Luc Noreau, Ph.D., who gave advice in the field of participation.

\section{References}

1. Theadom A, Rodrigues M, Roxburgh R, et al. Prevalence of muscular dystrophies: a systematic literature review. Neuroepidemiology 2014; 43:259-68.

2. Harper P. Myotonic dystrophy: a multisystemic disorder. In: Harper P, Van Engelen B, Eymard B, Wilcox D, editors. Myotonic dystrophy: present management, future therapy. Oxford, England: Oxford University Press; 2004. p 3-13.

3. Koch MC, Grimm T, Harley HG, Harper PS. Genetic risks for children of women with myotonic dystrophy. Am J Hum Genet 1991;48:1084-91.

4. Harley HG, Rundle SA, MacMillan JC, et al. Size of the unstable CTG repeat sequence in relation to phenotype and parental transmission in myotonic dystrophy. Am J Hum Genet 1993;52:1164-74.

5. De Antonio M, Dogan C, Hamroun D, et al. Unravelling the myotonic dystrophy type 1 clinical spectrum: a systematic registry-based study with implications for disease classification. Rev Neurol 2016;172:57280.

6. Campione E, Botta A, Di Prete M, et al. Cutaneous features of myotonic dystrophy types 1 and 2: implication of premature aging and vitamin D homeostasis. Neuromuscul Disord 2017;27:163-9.

7. Brisson D, Houde G, St-Pierre J, Vohl MC, Mathieu J, Gaudet D. The pleiotropic expression of the myotonic dystrophy protein kinase gene illustrates the complex relationships between genetic, biological and clinical covariates of male aging. Aging Male 2002;5:223-32.

8. Mateos-Aierdi AJ, Goicoechea M, Aiastui A, et al. Muscle wasting in myotonic dystrophies: a model of premature aging. Front Aging Neurosci 2015;7:125-41.

9. Natterlund B, Gunnarsson L-G, Ahlstrom G. Disability, coping and quality of life in individuals with muscular dystrophy: a prospective study over five years. Disabil Rehabil 2000;22:776-85.

10. Peric S, Stojanovic VR, Basta I, et al. Influence of multisystemic affection on health-related quality of life in patients with myotonic dystrophy type 1. Clin Neurol Neurosurg 2013;115:270-5.

11. Gagnon C, Mathieu J, Noreau L. Life habits in myotonic dystrophy type 1. J Rehabil Med 2007;39:560-6. 
12. Noreau L, Desrosiers J, Robichaud L, Fougeyrollas P, Rochette A, Viscogliosi C. Measuring social participation: reliability of the LIFE$\mathrm{H}$ in older adults with disabilities. Disabil Rehabil 2004;26:346-52.

13. Stiers W, Carlozzi N, Cernich A, et al. Measurement of social participation outcomes in rehabilitation of veterans with traumatic brain injury. J Rehabil Res Dev 2012;49:139-54.

14. Cicerone KD. Participation as an outcome of traumatic brain injury rehabilitation. J Head Trauma Rehabil 2004;19:494-501.

15. Fougeyrollas P. La funambule, le fil et la toile: transformations réciproques du sens du handicap. Québec: Presses de l'Université Laval; 2010.

16. Desrosiers J. Muriel Driver Memorial Lecture. Participation and occupation. Can J Occup Ther 2005;72:195-204.

17. Laberge L, Mathieu J, Auclair J, Gagnon É, Noreau L, Gagnon C. Clinical, psychosocial, and central correlates of quality of life in myotonic dystrophy type 1 patients. Eur Neurol 2013;70:308-15.

18. Larkindale J, Yang W, Hogan PF, et al. Cost of illness for neuromuscular diseases in the United States. Muscle Nerv 2013;49:431-8.

19. Gagnon C, Noreau L, Moxley RT, et al. Towards an integrative approach to the management of myotonic dystrophy type 1. J Neurol Neurosurg Psychiatry 2007;78:800-6.

20. Gagnon C, Chouinard MC, Laberge L, et al. Health supervision and anticipatory guidance in adult myotonic dystrophy type 1 . Neuromuscul Disord 2010;20:847-51.

21. Brady LI, MacNeil LG, Tarnopolsky MA. Impact of habitual exercise on the strength of individuals with myotonic dystrophy type 1. Am J Phys Med Rehabil 2014;93:739-50.

22. Ng SY, Manta A, Ljubicic V. Exercise biology of neuromuscular disorders. Appl Physiol Nutr Metab 2018.

23. Cup EH, Sturkenboom IH, Pieterse AJ, et al. The evidence for occupational therapy for adults with neuromuscular diseases: a systematic review. OTJR 2008;28:12-8.

24. Van Heugten C, Meuleman S, Hellebrekers D, Kruitwagen-van Reenen E, Visser-Meily J. Participation and the role of neuropsychological functioning in myotonic dystrophy type 1. J Neuromuscul Dis 2018;5:205-14.

25. Geirdal AØ, Lund-Petersen I, Heiberg A. Understanding the experience of myotonic dystrophy. Mixed method study. J Genet Couns 2015;24:169-78.

26. Cup EH, Kinebanian A, Satink T, et al. Living with myotonic dystrophy; what can be learned from couples? A qualitative study. BMC Neurol 2011;11:86.

27. LaDonna KA, Venance SL. Picturing the experience of living with myotonic dystrophy (DM1): a qualitative exploration using photovoice. J Neurosci Nurs 2015;47:285.

28. Bostrom K, Natterlund BS, Ahlstrom G. Sickness impact in people with muscular dystrophy: a longitudinal study over 10 years. Clin Rehabil 2005;19:686-94.

29. Mathieu J, Boivin H, Richards CL. Quantitative motor assessment in myotonic dystrophy. Can J Neurol Sci 2003;30:129-36.

30. Harper P. Looking ahead. Myotonic dystrophy: the facts. 2nd ed. New York: Oxford University Press; 2002. p 13-6.

31. Dogan C, De Antonio M, Hamroun D, et al. Gender as a modifying factor influencing myotonic dystrophy type 1 phenotype severity and mortality: a nationwide multiple databases cross-sectional observational study. PLoS One 2016;11:1-12.

32. Hammaren E, Kjellby-Wendt G, Lindberg C. Muscle force, balance and falls in muscular impaired individuals with myotonic dystrophy type 1: a five-year prospective cohort study. Neuromuscul Disord 2015;25:141-8.

33. Raymond K, Levasseur M, Mathieu J, Desrosiers J, Gagnon C. A 9year follow-up study of the natural progression of upper limb performance in myotonic dystrophy type 1: a similar decline for phenotypes but not for gender. Neuromuscul Disord 2017;27:673-82.

34. Laberge L, Veillette S, Mathieu J, Auclair J, Perron M. The correlation of CTG repeat length with material and social deprivation in myotonic dystrophy. Clin Genet 2007;71:59-66.
35. de Die-Smulders CE. Congenital and childhood-onset myotonic dystrophy. In: Harper P, van Engelen B, Eymard B, Wilcox D, editors. Myotonic dystrophy: present management, future therapy. Oxford, England: Oxford University Press; 2004. p 162-75.

36. Mathieu J, Prevost C. Epidemiological surveillance of myotonic dystrophy type 1: a 25-year population-based study. Neuromuscul Disord 2012;22:974-9.

37. Mathieu J, Boivin H, Meunier D, Gaudreault M, Begin P. Assessment of a disease-specific muscular impairment rating scale in myotonic dystrophy. Neurol 2001;56:336-40.

38. Komukai K, Fujimoto S, Sugita S, Mitsutake S, Wachigai H, Kobayashi M. Definitions and evaluation indexes of social participation in rehabilitation: a qualitative systematic literature review. Rigakuryoho Kagaku 2017:683.

39. Symonds T, Randall JA, Campbell P. Review of patient-reported outcome measures for use in myotonic dystrophy type 1 patients. Muscle Nerve 2016;56:86-92.

40. Levasseur M, Desrosiers J, Tribble DS. Comparing the disability creation process and international classification of functioning, disability and health models. Can J Occup Ther 2007;74:233-42.

41. Fougeyrollas P, Noreau L, Beaulieu M, et al. La Mesure des habitudes de vie (MHAVIE 3.1). Lac-St-Charles, Quebec, Canada: RIPPH; 2003.

42. Desrosiers J, Rochette A, Noreau L, Bourbonnais D, Bravo G, Bourget A. Long-term changes in participation after stroke. Top Stroke Rehabil 2006;13:86-96.

43. Gagnon C, Mathieu J, Noreau L. Measurement of participation in myotonic dystrophy: reliability of the LIFE-H. Neuromuscul Disord 2006; 16:262-8.

44. Desrosiers J, Noreau L, Robichaud L, Fougeyrollas P, Rochette A, Viscogliosi C. Validity of the Assessment of Life Habits (LIFE-H) in older adults. J Rehab Med 2004;36:177-82.

45. Hebert R, Carrier R, Bilodeau A. The Functional Autonomy Measurement System (SMAF): description and validation of an instrument for the measurement of handicaps. Age Ageing 1988;17:293302.

46. Labbé A, Noreau L, Bernard P-M, Fougeyrollas P. Reliability study of the life habits assessment in adults and children with traumatic brain injury [thesis dissertation]. Université Laval, Quebec, Canada; 1999.

47. Desrosiers J, Noreau L, Rochette A. Social participation of older adults in Québec. Aging Clin Exp Res 2004;16:406-12.

48. Bergner M, Bobbitt RA, Carter WB, Gilson BS. The Sickness Impact Profile: development and final revision of a health status measure. Med Care 1981;19:787-805.

49. Levasseur M, Desrosiers J, St-Cyr Tribble D. Subjective quality-of-life predictors for older adults with physical disabilities. Am J Phys Med Rehabil 2008;87:830-41.

50. Yang J, Hanna-Pladdy B, Gruber-Baldini AL, et al. Response shiftthe experience of disease progression in Parkinson disease. Parkinsonism Relat Disord 2017;36:52-6.

51. Peric S, Vujnic M, Dobricic V, et al. Five-year study of quality of life in myotonic dystrophy. Acta Neurol Scand 2016;134:346-51.

52. Peric S, Heatwole C, Durovic E, et al. Prospective measurement of quality of life in myotonic dystrophy type 1. Acta Neurol Scand 2017; 136:694-7.

53. Lazarus RS, Folkman S. Stress, appraisal, and coping. New York: Springer; 1984

54. Schwartz CE, Andresen EM, Nosek MA, Krahn GL; Measurement REPoHS. Response shift theory: important implications for measuring quality of life in people with disability. Arch Phys Med Rehabil 2007; 88:529-36.

55. Gallais B, Montreuil M, Gargiulo M, Eymard B, Gagnon C, Laberge L. Prevalence and correlates of apathy in myotonic dystrophy type 1. BMC Neurol 2015;15:148.

56. Baldanzi S, Bevilacqua F, Lorio R, et al. Disease awareness in myotonic dystrophy type 1: an observational cross-sectional study. Orphanet J Rare Dis 2016;11:1-11. 
57. Okkersen K, Jimenez-Moreno C, Wenninger S, et al. Cognitive behavioural therapy with optional graded exercise therapy in patients with severe fatigue with myotonic dystrophy type 1: a multicentre, single-blind, randomised trial. Lancet Neurol 2018;17:671-80.

58. Si-nae A, Eun-young Y, Min-ye J, Hae-yean P, Ji-yeon L, Yoo-im C. Comparison of cognitive orientation to daily occupational performance and conventional occupational therapy on occupational performance in individuals with stroke: a randomized controlled trial. NeuroRehabilitation 2017;40:285-92.
59. Scammell EM, Bates SV, Houldin A, Polatajko HJ. The Cognitive Orientation to daily Occupational Performance (CO-OP): a scoping review. Can J Occup Ther 2016;83:216.

60. Raymond É, Sévigny A, Tourigny A, Vézina A, Verreault R, Guilbert AC. On the track of evaluated programmes targeting the social participation of seniors: a typology proposal. Ageing Soc 2013;33:267-96.

61. Gallais B, Gagnon C, Mathieu J, Richer L. Cognitive decline over time in adults with myotonic dystrophy type 1: a 9-year longitudinal study. Neuromuscul Disord 2017;27:61-72. 